\author{
A. F. Osorio, S. Montoya-Vargas, C. A. Cartagena, J.J. Espinosa, A. Orfila, C. Winter
}

Abstract:

The wave peak period or peak frequency $\left(T_{p}\right.$ or $\left.f_{p}\right)$ is a statistical parameter commonly used to describe the energy spectrum of waves. It is important for the assessment of coastal structures, and wave modeling and prediction. In this paper, an image-based method for estimating the peak period of swell waves in near-shore environments is developed and validated. The method uses visual features of ocean waves presented in timestack images captured by video monitoring systems. The results of the

10 algorithm are compared to measured data from 4 beaches (Bunkerhill Beach, Sylt Island, Germany;

11 Cala Millor and Playa de Palma beaches, island of Mallorca, Spain; and Bocagrande beach,

12 Cartagena, Colombia) with different hydrodynamic and morphodynamic characteristics. The method

13 shows accurate results for $75 \%$ of the analyzed images despite the variable light conditions and noisy

14 signals. Errors for Cala Millor and Bocagrande beach are around $\sim 1$ s (mean error) and $\sim 1$ s (standard 15 deviation), which gives an error of less than $2 \mathrm{~s}$ for most of the results.

16 Keywords: Peak period; Peak frequency; Video imagery; Near-shore; Wave spectrum.

\title{
171 INTRODUCTION
}

18 The wave peak period or peak frequency $\left(T_{p}\right.$ or $\left.f_{p}\right)$ is a statistical parameter often used to describe 19 the energy spectrum of waves (Hasselmann, 1974; Huang et al., 1981; Mitsuyasu et al., 1975; Ochi 20 and Hubble, 1977; Soares, 1984), which is important for modeling the transformation of waves in 21 coastal areas (Grasmeijer and Ruessink, 2003; The SWAMP Group, 1985; The Wamdi Group, 1988).

22 Wave period data is important for evaluating the interaction of waves with human-built structures 
23 such as drilling platforms and harbors, among others. If the natural vibrational modes of these

24 structures coincide with the peak frequency of waves, resonance phenomena will lead to inoperability

25 or even failure (Bellotti, 2007). Overtopping of waves in seawalls and dikes depends on structure

26 parameters, such as the crest geometry and seaward slope, and on wave parameters, such as wave

27 height and peak period (dos Reis, 1998).

28 Peak period is commonly measured by installing in situ instruments and developing an extensive

29 field survey (for instance, the experimental setup described by Anctil \& Donelan, 1996; Hasselmann

30 et al., 1973; Larson \& Kraus, 1994; Ruggiero et al., 1999). In recent decades, technical developments

31 have allowed for the use of remote sensing based methods with lower costs compared to traditional

32 methods (Mumby et al., 1999). Some of these methods include those described in Mattie, Hsiao and

33 Evans (1981) where aerial photography and radar systems (SAR and coastal imaging radar) were

34 used to measure wave direction, showing agreement with installed pressure sensors. Recently, Zhang

35 and Zhang (2008) used sea surface video imagery to determine wave direction.

36 Many research projects have tried to solve the problem of lack of data in coastal areas by using

37 low cost, autonomous remote sensors, mainly near shore video-camera systems (Brignone et al.,

38 2012; Holman and Stanley, 2007; Nieto et al., 2010; Pérez Muñoz et al., 2013; Taborda and Silva,

39 2012). These have been used either for management purposes (Jiménez et al., 2007; Kroon et al.,

40 2007) or to provide direct and indirect morphodynamical data (Alexander and Holman, 2004; Catálan

41 and Haller, 2008; Hamylton, 2011; Múnera et al., 2014; Nieto et al., 2010; Osorio et al., 2012; Plant

42 and Holman, 1997; Smit et al., 2007). Today, video imagery is a mature technique widely used

43 worldwide to infer bathymetry in coastal areas, help in morphodynamical beach analyses to measure

44 wave height and celerity, or to estimate beach run-up. However, to date, little attention has been

45 devoted to the use of video systems to obtain the wave spectrum and peak period. An initial approach

46 presented by Holthuijsen (1981) applied stereographic techniques to aerial photographs generated in

47 Sylt (Germany). The sea surface elevations obtained were subjected to spectral analysis in the 
frequency and space domain. Yim et al. (2006) applied a three dimensional Fourier transform to radar

49 images from Taipei Harbour showing that the square root of the zero-th moment of the power 50 spectrum of the images was correlated with the significant wave height in a linear way. They also 51 showed that the directional wave rose obtained from the radar images displayed similar patterns to 52 those acquired from current meters installed at the study site. Recently, Greenwood et al. (2018) used 53 X-band radar signals to approximate the sea surface. The energy spectrums generated from sea 54 surface approximation were in excellent agreement with those generated from buoy recordings.

55 Although high spatial resolution and relatively large coverage can be obtained by means of aerial 56 photography and radar systems, these measuring techniques are still expensive, making alternatives 57 such as that presented by Chou et al. (2004) more attractive. In their work, the water surface 58 fluctuations in a wave basin were analyzed using CCD cameras, showing that pixel brightness and 59 wave gauge recordings are strongly correlated for both regular and irregular wave conditions. 60 However, their work was limited to laboratory environments in which the brightness conditions were 61 carefully controlled to minimize the noise produced by brightness fluctuations.

62 Later, Yoo et al. (2005) used video image analysis techniques to estimate wave parameters at 63 Myrtle Beach, South Carolina (USA). Video estimations of wave period for one day of data gives the 64 most common result $(10 \mathrm{~s})$ while spectral analysis of measured wave data shows $T_{p}$ to be $10.4 \mathrm{~s}$. 65 However, no accuracy analysis was presented by Yoo et al. Zikra et al. (2011) obtained directional 66 wave spectra from pixel intensity series extracted from video image sequences. These were collected 67 by a single digital video camera installed on Hasaki beach (Japan). Normalized frequency spectra, as 68 well as directional spectra obtained from the images, show satisfactory agreement with wave gauge 69 measurements and SWAN numerical models. The images used by Zikra were subjected to visual 70 inspection before the analysis was carried out.

71 Recently, Abessolo Ondoa et al. (2016) used video image analysis techniques previously reported 72 by Lippmann and Holman (1991) and Stockdon \& Holman (2000) to estimate $T_{p}$ at Grand Popo beach, 
73 Benin. The method used for calculating peak frequencies was based on spectral analysis of pixel

74 intensity time series and filtering procedures in order to avoid noisy signals. Although in the work of 75 Abessolo Ondoa et al. the video image estimations of $T_{p}$ were close to the measurements (root mean 76 square error, RMSE= $1.31 \mathrm{~s}$ ), the accuracy could be improved by applying further pre-processing 77 steps before spectral analysis. At James Town Beach in Ghana, a similar approach for estimating $T_{p}$ 78 was adopted by Angnuureng et al. (2016). The results were in good agreement with hindcast modeled 79 data $\left(\mathrm{R}^{2}=0.9\right.$ and $\left.\mathrm{RMSE}=0.7\right)$, but a comparison with field data is missing from their study.

80 The works of Yoo et al. (2005), Zikra et al. (2011), Angnuureng et al. (2016), and Abessolo Ondoa 81 et al. (2016) suggest that video camera systems can be used to estimate wave spectra in uncontrolled 82 illumination environments. However, these studies are not conclusive since they used a limited 83 number of sites and uncertainty and accuracy analysis was not carried out. Moreover, it is important 84 to avoid visual inspection of the images in order to achieve automaticity of the method without loss 85 of accuracy. The aim of this paper is to present a method for estimating nearshore wave spectrum 86 parameters, specifically the peak period, based on image analysis techniques and video monitoring 87 systems. Novel contributions presented herein include the validation of the method in four locations 88 with different hydrodynamic and morphodynamic conditions, as well as an improved processing 89 method in which automated treatment of noisy signals produced by environmental illumination 90 fluctuations is implemented. The paper is structured as follows: first the main features of the study 91 sites are introduced; second, sources of data series used to validate the method are presented and 92 detailed; third, image acquisition systems are described for each site; fourth the algorithm is 93 developed in detail and the results are shown; and finally, the summary and conclusions are presented. FIG 1. Study sites: (a) Bunkerhill beach; (b) Playa de Palma and Cala Millor beaches; and (c) 
2 STUDY SITES

\section{Bunkerhill beach.}

This study area is situated on Bunkerhill Beach on the west coast of Sylt. The island of Sylt is part of the North-Frisian Islands, a chain of barrier islands located in the German Bight [see figure 1(a)]. Bunkerhill Beach is a high-energy beach with mean significant wave heights $H_{\mathrm{s}}$ between $1 \mathrm{~m}$ to 1.2 $\mathrm{m}$ and mean wave periods between $3 \mathrm{~s}$ to $5 \mathrm{~s}$ (Blossier et al., 2017). The tidal range is about $2 \mathrm{~m}$. The beach can be categorized as an intermediate type beach with high seasonal variations (Menn, 2002).

\section{Cala Millor and Playa de Palma beaches.}

These two beaches are micro-tidal sandy beaches located on the island of Mallorca in the Mediterranean Sea [see figure 1(b)]. Cala Millor is exposed to offshore waves from the NE to ESE while Playa de Palma beach is exposed to offshore waves from the SE and SW. According to Enríquez et al. (2017), on Playa de Palma beach significant wave height $\left(H_{s}\right)$ in deep water has values of between $0.3 \mathrm{~m}$ and $1.6 \mathrm{~m}$, with peak periods $\left(T_{p}\right)$ varying between $3 \mathrm{~s}$ and $7 \mathrm{~s}$. On the other hand, for Cala Millor beach, $H_{s}$ varies between $0.4 \mathrm{~m}$ and $2.5 \mathrm{~m}$, and $T_{p}$ varies between $3.7 \mathrm{~s}$ and $9.3 \mathrm{~s}$. Moreover, both beaches display low-energy wave conditions, with Cala Millor being more energetic than Playa de Palma.

\section{Bocagrande beach.}

Bocagrande beach is a micro-tidal sandy beach located in the city of Cartagena on the Caribbean coast of Colombia [see figure 1(c)]. Tides in the study zone are mixed diurnal micro-tides with an amplitude of less than $0.50 \mathrm{~m}$. Surge has a strong effect on the mean sea level, often making it rise by $0.15-0.20 \mathrm{~m}$. Wind waves come from the $\mathrm{N}$ and $\mathrm{NE}$ directions with an average height of $0.25 \mathrm{~m}$. There are also waves that come from the E direction with an average height of $0.5 \mathrm{~m}$ to $1 \mathrm{~m}$ (CondeFrias et al., 2017). Peak periods in the range of 3 to 14 seconds can appear on this beach, the most common being between $6 \mathrm{~s}$ and $8 \mathrm{~s}$. 


\section{$121 \quad 3.1$ VALIDATION DATA}

122 Available data for the study sites is presented in terms of significant wave height $\left(H_{s}\right)$ and peak 123 period/frequency $\left(T_{p}\right.$ or $\left.f_{p}\right)$. The wave spectrum is generally unavailable. The estimation of significant

124 wave height from video imagery requires the application of stereographic techniques and at least two 125 cameras focusing on the same region (de Vries et al., 2011). Because such a configuration was not 126 considered in the video monitoring systems available, it was not possible to measure $H_{s}$ from video 127 imagery. Therefore, validation of the algorithm was limited to comparison against the measured $T_{p}$. 128 For the Bunkerhill site, the data was obtained from records of the HZG COSYNA wave buoy 129 Bunkerhill1 located approximately $1 \mathrm{~km}$ seaward from the shore at the study site [red dot in Figure 130 1(a)]. The data covers the period from 30th-May-2014 to 1st-October-2014. For Cala Millor and 131 Playa de Palma beaches, $T_{p}$ was recorded using two directional acoustic waves and Currents 132 (AWAC), covering the period from 9th-January-2014 to 31st-December-2014. The measurements 133 were carried out as part of the beach-monitoring program of the Balearic Islands Coastal Observing 134 and Forecasting System (SOCIB) and the Mediterranean Institute for Advanced Studies (IMEDEA). 135 For Bocagrande, the $T_{p}$ series was also obtained using an AWAC (see red dot in Figure 1(c) for its 136 location). Hourly data were collected from February 11th to 13th 2011.

\section{$137 \quad 3.2$ CAMERA SYSTEMS/ IMAGE DATA}

138 Time-stack images for Sylt were obtained from a camera system implemented by the Coastal 139 Dynamics Group (MARUM). Time-stacks were recorded at 4 frames per second for approximately 14019 minutes (Blossier et al., 2017). The images correspond to 25 days between July and October 2014. 141 They were recorded at different times, but most commonly at 10:00 UTC. 
142 Time-stack images for Cala Millor and Playa de Palma beaches were obtained from the video143 based coastal zone monitoring system SIRENA developed by SOCIB and IMEDEA (Nieto et al., 144 2010). Time-stacks used in this work correspond to 10 different days between January and July 2014, 145 at 09:00, 12:00 and 15:00 UTC. The time-stacks recorded by the SIRENA system were taken at 7.5 146 frames per second for 10 minutes.

147 Time-stacks for Cartagena were generated from video imagery captured by the video monitoring 148 system HORUS implemented in the study zone by the Oceanography and Coastal Engineering 149 Research Group (OCEANICOS) from the Universidad Nacional de Colombia and Universidad de 150 Cantabria (Múnera et al., 2014; Pérez Muñoz et al., 2013). Videos were recorded for the same period 151 and time as measured data, with a rate of 1.85 frames per second for 17 minutes.

\subsection{ALGORITHMS}

153 As demonstrated theoretically by Jähne and Schultz (1992), the pixel intensity registered by a video 154 camera varies with the slope of the observed surface. This phenomenon is also known as specular 155 reflection of downwelling sky radiance (Stockdon and Holman, 2000), and makes the seaward face

156 of the wave be brighter than the landward face (see Figure 2). Therefore, time series of pixel intensity 157 for a particular pixel in the video image will follow an oscillatory signal from lower to higher 158 brightness (produced by passing waves through the specific pixel location). This would give an 159 approximately equal shape to that given by surface elevation series if they were measured, as shown 160 by Chou, Yim and Huang (2004) and Zikra (2012). Since a time series has similar patterns, spectral 161 representation in the frequency domain of both pixel intensity and surface elevation series presents a 162 similar shape and position, hence the peaks of both spectrums are allocated near the same frequency. 163 This particular frequency is defined as the peak frequency. Calculating the peak frequency from the 164 pixel intensity spectrum will coincide with the peak frequency of the wave height spectrum, a feature 165 used in this work to estimate the peak frequency of waves. 
166 The proposed method uses time-stack images rather than video records. Time-stack images can be 167 understood as a concatenation of a particular pixel column extracted from video images at different 168 frames or times [see Figure 3(a)]. In Figure 3(b), the resulting time-stack shows pixel columns in the

169 vertical ordinate that are concatenated horizontally, giving time or frames in the horizontal ordinate.

170 Each row of the timestack image represents a pixel intensity time series of one point in the video. An 171 example of the pixel intensities stored in one row of a timestack composed of 4500 frames is shown 172 in Figure 4.

173 Prior to the spectral analysis, some filtering has to be performed in order to remove noisy signals 174 and spectral leakage. Noisy signals come from different features in time-stack images, such as 175 illumination changes through the record [Figure 5(a)], roller foam developed by broken and breaking 176 waves [Figure 5(b)], direct sunlight hitting the sea surface [Figures 6(a) and 6(b)] or glittering caused 177 by the sun [Figure 6(c) and 6(d)]. Other factors might be environmental and climatic conditions. 178 Spectral leakage arises from the lack of periodicity of finite signal sampling contrary to the assumed 179 periodicity in Fourier transform. This generates frequencies in the spectrum that are not present in the 180 true signal or produces spilling of those which are present (Harris, 1978). The operations applied to 181 filter the time series are described in the next section. FIG 2. Visual wave features: dark frontal face and bright back face. FIG 3. Time-stack image: (a) pixel column concatenation; and (b) resulting time-stack. FIG 4. Example of one row of pixel intensity time series.

186 FIG 5. Sources of noise in timestack images: (a) Environmental illumination (clouds) changes viewed in time-stack image; (b) Foam from breaking waves viewed in time-stack image. 
FIG 6. Sources of noise in timestack and snapshot images: incidence of direct sunlight in $(a)$ snap-shot image and $(b)$ time-stack image; and sun glittering in $(c)$ snap-shot image and $(d)$ timestack image.

\subsubsection{Treating breaking waves and sunlight saturation}

The foam of breaking waves is inherent in the surf zone. Therefore, it is necessary to limit the region of analysis to that in which foam is not present. Foam is easily identified by its white color contrasting with dark tones of seawater. The thresholding method proposed by Otsu (1979) has been adopted here to identify the zone of non-breaking water in the image. This zone is used to obtain the pixel intensity time series. Since sunlight saturated regions of the image (i.e., sun incidence) present higher pixel intensities, thresholding can also identify the saturated regions.

It was observed that when the region remaining after thresholding is too small (let's say 5 rows or less), the analysis produces inaccurate results. A discarding criteria is recommended when the timestack image presents excessive saturation or a large breaking zone compared with the non-breaking zone. In this work, the criterion applied was the number of remaining rows, and rejection occurred when there were less than 5 rows available for analysis.

\subsubsection{Noisy signals treatment.}

As already stated, the pixel intensity time series obtained from video imagery is contaminated by noise from multiple sources related to sunlight variations of both the water surface and the environment. This noise can be removed using a band-pass filter that removes periodic signals which are outside a particular band of frequencies defined by a low cut-off frequency and a high cut-off frequency. The filter consists of a convolution of a transfer function and the signals. The function shapes the frequency spectrum in a way that amplitudes inside the range of target frequencies are preserved while others are led to zero (Oppenheim, 2011). In general, it is desired that the shape of the filter approaches a rectangle with a width equal to the frequency band and a gain equal to 1 in 
212 order to preserve the shape of the spectrum inside the bandwidth. Here, the Butterworth filter was

213 selected for its ability to meet these requirements (see Figure 7). However, other filters can be used

214 depending on the specific noise to be eliminated. Three parameters are used to describe the

215 Butterworth filter: low and high cut-off frequencies and the filter order. The latter defines how fast

216 the amplitude of the spectrum changes from 1 inside the band of frequencies to 0 outside the band.

217 The filter order was set to 10 in order to approach a rectangular shape.

FIG 7. Butterworth filter shape for different filter orders $(\mathrm{N})$.

219 Selecting the cut-off frequencies was a more difficult task. As a first approximation, it was defined 220 that they should contain the typical range of frequencies presented in sea wind waves (Munk, 1951), 221 going from $0.03 \mathrm{~Hz}$ (period of 30 seconds) to $0.5 \mathrm{~Hz}$ (period of 2 seconds). However, it was found 222 that noisy signals caused by environmental light variation were contained within this range (e.g. 0.07 $223 \mathrm{~Hz}$ for many images). Thus, a low cut-off frequency identification method was applied before the 224 signals were processed. The method approaches the cut-off frequency by estimating the main 225 frequency of the noisy signal. The only input needed for this purpose is a series from the noisy signal. 226 As seen in Figure 8(a), environmental changes in light are present on both the sea surface and the 227 nearshore landscape. The water surface contains mixed signals of both surface variation and 228 environmental brightness fluctuation, with the latter being difficult to isolate. On the other hand, the 229 land region contains environmental sunlight signals only, meaning that it is adequate to obtain noise 230 signals whose periodicity ranges between $0.03 \mathrm{~Hz}$ and $0.5 \mathrm{~Hz}$. Fast Fourier Transform (FFT) was 231 applied to the land pixel intensity series [see Figure 8(b)] and the frequency of the spectrum peak was 232 selected as the low cut-off frequency [Figure 8(c)]. Because some spectra display multiple peaks in a 233 narrow neighborhood of frequencies [as shown in Figure 8(c)], the spectra were smoothed and the 234 peak frequency was incremented by a factor of 0.3 in order to take into account its width. However, 235 the cut-off frequency must not be less than $0.03 \mathrm{~Hz}$ due to the physical reasons explained above. In 
236 Figure 8(c), the peak spectrum is located at a frequency of $0.044 \mathrm{~Hz}$, and an increment of $30 \%$ gives

2370.0572 (equivalent to a period of $17.5 \mathrm{~s}$ ) for the low cut-off frequency.

FIG 8. Environmental sunlight noise: (a) time-stack image feature; (b) average pixel intensity series in a land region; (c) corresponding spectral representation.

\subsubsection{Spectral leakage treatment.}

Spectral leakage can be minimized by softening the time series near the ends such that the finite sample achieves periodicity when extended successively in the time domain (see Figure 9). For this purpose, the time series are modulated by a window function whose shape goes from 1 near the middle of the sample to 0 at the ends. There are multiple window functions which can be used.

FIG 9. Non-periodic extension for a sample of periodic series.

As shown by Harris (1978), windowing affects the frequency spectrum similar to the impact produced by the filtering process. Therefore, the window function must be carefully chosen in order to avoid spectral distortion of the series. In this work, well know features of the shape of swell wave spectra were the basis in determining an adequate window function. These features were:

(i) no presence of harmonics at $0 \mathrm{~Hz}$ frequency (i.e. series mean set to 0 )

(ii) fast decay of the spectrum at saturation frequencies, and

(iii) clear definition of multiple peaks if they were present.

Following the work of Harris (1978), adequate windowing functions for these purposes are Tuckey, Blackman, and Chebyshev windows. A sensitivity analysis was done in order to detect the sensitivity of windowing to filtering (i.e. frequency filtering). It was found that the Blackman window was the least sensitive to the filtering process so it was selected as the window function. The results of the sensitivity analysis for windowing are presented in the following sections.

\subsubsection{Spectral analysis: Fast Fourier Transform.}


After the filtering process, time series are displayed in the frequency domain by means of a Fast

260 Fourier Transform (FFT). The spectrum obtained is virtually free of noise signals and leakage, and

261 the estimated peak frequency is more reliable. The peak period is estimated as the multiplicative

262 inverse of the peak frequency.

263 Because each row in the time-stack represents a pixel intensity series, there are multiple peak

264 frequencies (one per row). Therefore, the mean spectra shape should be used before identifying the

265 peak frequency. It should be noted that the results are practically insensitive to either taking the

266 average of the peak frequencies and then estimating the peak period from this value or calculating the

267 peak period as the mean value of peak period of each row.

268 The algorithm is summarized in the flowchart presented in Figure 10. In order to attain a better 269 understanding of each step, the effects of each step in the time series and their influence on the 270 accuracy of the algorithm are illustrated in the following sections.

\section{$271 \quad 4$ RESULTS}

272 This section presents the output results, step by step in order to give a better understanding of the 273 algorithm, the effect of each step and how they improve the peak period estimation. The accuracy of 274 the method for each site is also presented and discussed.

\subsection{Step 1: Binarization}

276 A time-stack image using Otsu thresholding is shown in [Figure 11(a)] and then binarized [Figure

277 11(b)]. In the binarized image, breaking waves are identified by white regions while foam-free surface

278 is identified by black regions. Selecting only the black regions results in an image of free breaking 279 waves [see Figure 11(c) and the dashed-line marked region in Figure 11(a)]. 
As mentioned above, the raw pixel intensity series presents noisy signals shown in Figure 12 (a) corresponding to the time-stack presented in Figure 8 (a). The resulting spectrum of this series [Figure

28312 (b)] is still different from typical wind wave spectra, presenting a large peak near the 0 frequencies 284 and a negligible and nearly constant amplitude at the remaining frequencies. When the low cut-off 285 frequency is identified and the filtering process is applied, the resulting mean of the series is set to 0 286 [see Figure 12(c)] while the corresponding spectrum looks like a typical ocean wave spectrum [see 287 Figure 12(d)].

\subsection{Step 3: Windowing}

As mentioned in section 3.3.3, the windowing procedure modifies the shape of the signal spectra.

290 It was found that, for different window functions, the peak of the spectra varies its position to a higher 291 or lesser degree (i.e., affecting the accuracy of the $T_{p}$ estimation) depending on the selected cut-off 292 frequencies. Since the cut-off frequency could vary among the images, the windowing function used 293 in the analysis must be as insensitive to the cut-off frequency as possible. In order to select the window 294 with this characteristic, a sensitivity analysis was carried on a sample of time-stack images from 295 Bunkerhill beach. In the analysis, the low cut-off frequency was varied and the Tuckey, Chebyshev 296 and Blackman windows were applied. The estimations of $T_{p}$ for each combination of window function 297 and cut-off frequency are plotted against measured values of $T_{p}$ in Figure 13. The results obtained 298 with the Chebyshev window are not presented here since it produced the same results as the Blackman 299 window. The mean and standard deviation of error are summarized in Table 1, showing that 300 Blackman (or Chebyshev) windows are the most suitable due to the low mean error variations in 301 comparison with the Tuckey window when the cut-off frequency is changed. Since the Chebyshev 302 and Blackman windows produced the same results, the selection of one or the other would seem to 303 be arbitrary. 

values (i.e., $T_{p}$ values) can be generated from a single time-stack image. In order to obtain a single

307 value for each time-stack, the data generated from each row must be averaged. However, this could 308 be done in different ways. The first approach consists of determining the peak frequency from the 309 averaged spectra $(\langle S\rangle)$ of all the rows in the time-stack. The average spectra $\langle S\rangle$ are computed 310 according to Eq. (1), where $S_{i}$ is the spectra for row $i$ and $n$ the number of rows analyzed after 311 thresholding. Another way is to obtain a peak frequency from each row and then average the data 312 according to Eq. (2), where $i$ and $n$ have the same meaning as in Eq. (1). The corresponding peak 313 period value can be obtained as $\left(\left\langle f_{p}\right\rangle\right)^{-1}$. On the other hand, $T_{p}$ values can be computed for each row 314 as $f_{p}^{-1}$ and then the average value $\left\langle T_{p}\right\rangle$ could be taken as the corresponding peak period of the time315 stack following Eq. (3) which is mathematically different to Eq. (2). Selected rows.

Table 1. Peak Period Error Analysis of Windows: BM denotes the Blackman window; TK denotes the Tuckey window.

FIG 12. Pixel intensity time series processing: Unfiltered time series - (a) Pixel intensity series and (b) Frequency spectrum; Filtered time series - (c) Pixel intensity series and (d) Frequency spectrum; and Windowed time series - (e) Pixel intensity series and (f) Frequency spectrum. 
330 In order to select the procedure that achieved the maximum accuracy, these three approaches were

331 tested and compared using the mean error. Comparison of the approaches was made using the mean

332 error (M.E.) of the estimation. The error was computed according to equation (4), where $P$ represents

333 the estimated (i.e., Predicted) $T_{p}$ and $O$ represents the measured (i.e., Observed) $T_{p}$. The values of $T_{p}$

334 from each approach were plotted against the measured $T_{p}$ and are presented in Figure 14.

$$
\text { Error }=|P-O|
$$

336 As mentioned earlier, the approach adopted to calculate the peak period has no significant effect 337 on the accuracy of the estimation.

\subsection{Overall accuracy}

339 The complete algorithm was applied for 105 arbitrarily selected images and when the resulting 340 peak period was compared with the measured data it showed a strong agreement (Figure 15). In order

341 to assess the accuracy and capabilities of the proposed method, the mean and standard deviation of 342 the error were computed. The correlation coefficient $(r)$ and index of agreement $(d)$ (Willmott, 1981) 343 were also computed. Error was calculated according to equation (4), while $r$ and $d$ were calculated 344 following equations (5) and (6), respectively. In equation (5), $\sigma_{O P}$ is the covariance between the 345 estimated and measured values of $T_{p} . \sigma_{O}$ and $\sigma_{P}$ are the standard deviation of the measured and 346 estimated $T_{p}$, respectively. In equation (6), $P$ and $O$ has the same meaning as in equation (4), while $347 \mu_{O}$ represents the mean value of the measured data and $n$ the length of the data.

$$
r=\frac{\sigma_{O P}}{\sigma_{O} \sigma_{P}}
$$




$$
d=1-\frac{\sum_{i}^{k}\left(O_{i}-P_{i}\right)^{2}}{\sum_{i}^{k}\left(\left|P_{i}-\mu_{O}\right|+\left|O_{i}-\mu_{O}\right|\right)^{2}}
$$

350 The mean error is $\mu=1.38 \mathrm{~s}$ and the standard deviation is $\sigma=2 \mathrm{~s}$ for the whole data. The correlation 351 coefficient is $r=0.6$ and the index of agreement is $d=0.78$. However, some images ( 13 in total) present 352 errors larger than $\mu+\sigma=3.38$ s. For 8 of these images, the low cut-off frequency was not identified 353 accurately by the proposed approach, forcing the peak of the spectrum to be located at low 354 frequencies. For the remaining 5 images, the peak frequency coincides with the cut-off frequency. 355 The correct peak of the spectrum was then eliminated and the next peak in the spectrum was identified 356 by the algorithm. Therefore, the estimated frequencies were higher than the measured frequencies 357 (i.e. the estimated peak periods are lower than the measured ones). Excluding these data from the 358 analysis, the error sets a mean value of $\mu=0.71 \mathrm{~s}$, with a standard deviation of $\sigma=0.67 \mathrm{~s}$, and 0.93 359 and 0.96 for $r$ and $d$, respectively.

FIG 14. Comparison of peak period approaches.

FIG 15. Estimated vs. measured $T_{p}$ for the whole data set.

\subsection{Accuracy of the method according to site conditions}

363 Scatter plots of measured vs. estimated values of peak period, discriminated according to site, are 364 provided in Figure 16(a)-(d) for Cala Millor, Playa de Palma, Bunkerhill and Bocagrande beaches, 365 respectively. Dashed lines indicate the upper and lower bounds errors. Table 2 summarizes the mean 366 absolute error, the standard deviation, and the agreement parameters $r$ and $d$ for each site.

Table 2. Error and agreement parameters for the study sites.

The mean and standard deviation for the error are larger for the Bunkerhill and Playa de Palma

369 beaches. In the case of Playa de Palma beach, the loss of accuracy is caused by some misleading 370 estimations of the error around $6 \mathrm{~s}$ (see dots outside dashed line in Figure 16 (b)). As already stated, 
371 these discrepancies are caused because the low cut-off frequency identification procedure gives a cut372 off frequency of 2 to 4 seconds, which coincides with the current peak period of the waves. Therefore, 373 the estimated peak period is shifted to the next peak in the image spectrum, located at a period of 374 approximately 9 seconds. The same situation occurs for periods between 4 and $6 \mathrm{~s}$ on Bunkerhill 375 beach. Also, under higher energy conditions (i.e., $T_{p}$ over $10 \mathrm{~s}$ ) the peak periods are underestimated 376 for Bunkerhill beach. By inspecting the timestack images corresponding to these data, permanent 377 foam can be observed. The noisy signal that was produced was not correctly eliminated by the 378 thresholding procedure, thereby affecting the results. However, despite the large errors introduced by 379 erroneous results, the index of agreement remains at over 0.7 for both sites, indicating that the 380 estimated peak periods are in satisfactory agreement with the measured data. FIG 16. Estimated vs. measured $T_{p}$ for: (a) Cala Millor beach; (b) Playa de Palma beach; $(c)$ Bunkerhill beach; and (d) Bocagrande beach.

384 Millor, the accuracy is supported by the agreement parameters, which have values of over 0.8. For 385 Bocagrande beach, the agreement parameters are lower despite the small error caused by the limited 386 range of measurements.

387 It is assumed that values of error of less than $2 \mathrm{~s}$ represent a satisfactory estimation of the peak period because beyond this value energy conditions associated to the estimated $T_{p}$ will differ from the real conditions by an appreciable amount. From the set of estimated $T_{p}, 19$ present an absolute error greater than $2 \mathrm{~s}$. This represents $18 \%$ of the analyzed images. Generally, energy conditions associated

391 to the larger errors in the estimated $T_{p}$, where there are conditions of high energy for Bunkerhill beach and low energy for Playa de Palma, suggest that accurate estimations are achieved principally for medium energy conditions. Although this could be a limitation of the proposed method, medium energy conditions are presented in most cases. In fact, $82 \%$ of the analyzed images present a satisfactory estimation of the peak period. 


\section{DISCUSION AND CONCLUSIONS}

397 In the work of Zikra et al. (2011), the root-mean-square error (RMSE) of $f_{p}$ derived from video 398 images was $0.02 \mathrm{~Hz}$, while a value of $0.07 \mathrm{~Hz}$ was obtained for the whole data set. The large error 399 obtained in comparison with the work of Zikra et al. is attributed to the inaccurate results taken from 400 images captured during high and low energy conditions. In the current study, the measured value of $401 f_{p}$ varies between 0.06 and $0.5 \mathrm{~Hz}$ (or $T_{p}$ between 2 and $16 \mathrm{~s}$ ), while the peak frequencies measured 402 by Zikra et al. vary between 0.09 and $0.13 \mathrm{~Hz}\left(T_{p}\right.$ between 7.7 and $\left.11.1 \mathrm{~s}\right)$ which represent medium 403 energy sea states. When analyzing the Bocagrande beach data (where medium energy conditions were 404 measured), the RMSE was found to be $0.02 \mathrm{~Hz}$, showing that a similar accuracy can be obtained.

405

Recently, Abessolo Ondoa et al. (2016) obtained a $T_{p_{-} R M S E}$ of $1.31 \mathrm{~s}$, while a value of $0.7 \mathrm{~s}$ was obtained for the whole data set. The method proposed by Stockdon \& Holman (2000) for calculating peak frequencies is also based on the spectral analysis of pixel intensity time series, but differs with the present method in the filtering procedure. According to Stockdon \& Holman, bandpass filtering uses 0.05 and $0.5 \mathrm{~Hz}$ as low and high cut-off frequencies for every image, in contrast with the present method in which a suitable low cut-off frequency is estimated for each image.

From the discussion above, it is suggested that carrying out the proposed processing steps previous to the spectral analysis improves the overall accuracy of the method. It is worth noting that no visual examination of the images was performed before analysis, thereby achieving automaticity of the method. However, during high and low energy sea states, the algorithm can lead to inaccurate results. As a final conclusion, and to summarize the contribution of this work, a novel approach for estimating spectral parameters of swell waves in near-shore environments, specifically the peak period, has been presented and validated. The present method is based on video image analysis and signal processing techniques. It has been demonstrated that applying signal processing techniques improves the results of the algorithm. The parameters of the signal processing elements were selected based on the physical phenomena. The method exposes the powerful capabilities of near-shore video monitoring 
421 systems to automatically detect the peak period of near-shore waves with reasonable accuracy. This

422 is achieved without taking into account the camera configuration and requires only that a 423 representative amount of land pixels appear in the images in order to adequately eliminate noisy 424 signals produced by environmental light fluctuations. From the whole set of analyzed data, only 18 425 images present an error greater than $2 \mathrm{~s}$, while another 10 images not included in the plot were not 426 suitable for analysis (less than 5 rows remain after the binarization process). Nearly $75 \%$ of the 427 database (87 images out of a total of 115 were shown to be suitable for the analysis) produced accurate 428 results, therefore suggesting that the technique has a promising future. Some limitations were found 429 in the application of the automatized method for images showing extremely low-energy conditions, 430 i.e., $T_{p}<4 \mathrm{~s}$ for Playa de Palma and Cala Millor beaches, and $T_{p}$ between 4 and 6 seconds for 431 Bunkerhill beach. The same was found for high-energy conditions, i.e., $T_{p}>10 \mathrm{~s}$ for Bunkerhill beach. 432 Future lines of research should include the estimation of other spectral parameters, such as the height 433 of the peak in the spectrum (i.e., $H_{s}$ ) and the directional distribution of wave energy.

\section{ACKNOWLEDGEMENTS}

435 The work described in this paper is part of a research project entitled "Analysis of the 436 hydrodynamic and morphodynamic characteristics of a sandy beach by means of numerical modeling 437 and image processing”. It is being carried out in the Department of Geoscience and the Environment, 438 which is part of the Faculty of Mines at the Universidad Nacional de Colombia. The project is funded 439 by research grants made available by the Universidad Nacional through the "National call for projects 440 to strengthen research, creation and innovation at Universidad Nacional de Colombia" (Convocatoria 441 Nacional de proyectos para el fortalecimiento de la investigación, creación e innovación de la 442 Universidad Nacional de Colombia). These resources are gratefully acknowledged. The authors also 443 wish to express thanks to the OCEANICOS and MARUM research groups, and the SOCIB and 444 IMEDEA monitoring programs for the data they provided. Data from the HZG COSYNA 
"Bunkerhill" wave buoy was obtained from an open website. Finally, the helpful comments made by 446 the reviewers are appreciated.

\section{REFERENCES}

Abessolo Ondoa, G., Almar, R., Kestenare, E., Bahini, A., Houngue, G.-H., Jouanno, J., Du Penhoat, Y., Castelle, B., Melet, A., Meyssignac, B., Anthony, E.J., Laibi, R., Alory, G., Ranasinghe, R., 2016. Potential of Video Cameras in Assessing Event and Seasonal Coastline Behaviour: Grand Popo, Benin (Gulf of Guinea). J. Coast. Res. https://doi.org/10.2112/SI75089.1

Alexander, P.S., Holman, R.A., 2004. Quantification of nearshore morphology based on video imaging. Mar. Geol. 208, 101-111. https://doi.org/10.1016/J.MARGEO.2004.04.017

Anctil, F., Donelan, M.A., 1996. Air-Water Momentum Flux Observations over Shoaling waves. J. Phys. Oceanogr. 26, 1344-1353. https://doi.org/10.1175/15200485(1996)026<1344:AMFOOS>2.0.CO;2

Angnuureng, D.B., Almar, R., Appeaning Addo, K., Castelle, B., Senechal, N., Laryea, S.W., Wiafe, G., 2016. Video Oberservation of Waves and Shoreline Change on the Microtidal James Town Beach in Ghana. J. Coast. Res. 75, 1022-1026. https://doi.org/10.2112/SI75205.1

Bellotti, G., 2007. Transient response of harbours to long waves under resonance conditions. Coast. Eng. 54, 680-693. https://doi.org/10.1016/J.COASTALENG.2007.02.002

Blossier, B., Bryan, K.R., Daly, C.J., Winter, C., 2017. Spatial and temporal scales of shoreline morphodynamics derived from video camera observations for the island of Sylt, German Wadden Sea. Geo-Marine Lett. 37, 111-123. https://doi.org/10.1007/s00367-016-0461-7 
Brignone, M., Schiaffino, C.F., Isla, F.I., Ferrari, M., 2012. A system for beach video-monitoring: Beachkeeper plus. Comput. Geosci. 49, 53-61. https://doi.org/10.1016/J.CAGEO.2012.06.008

Catálan, P.A., Haller, M.C., 2008. Remote sensing of breaking wave phase speeds with application to non-linear depth inversions. Coast. Eng. 55, 93-111. https://doi.org/10.1016/J.COASTALENG.2007.09.010

Chou, C.R., Yim, J.Z., Huang, W.P., 2004. Determining the hydrographic parameters of the surface of water from the image sequences of a CCD camera. Exp. Fluids 36, 515-527. https://doi.org/10.1007/s00348-003-0664-3

Conde-Frias, M., Otero, L., Restrepo, J.C., Ortiz, J.C., Ruiz, J., Osorio, A.F., 2017. Swash Oscillations in a Microtidal Dissipative Beach. J. Coast. Res. 336, 1408-1422. https://doi.org/10.2112/JCOASTRES-D-16-00147.1

de Vries, S., Hill, D.F., de Schipper, M.A., Stive, M.J.F., 2011. Remote sensing of surf zone waves using stereo imaging. Coast. Eng. 58, 239-250. https://doi.org/10.1016/J.COASTALENG.2010.10.004

dos Reis, M.T.L.G.V., 1998. Probabilistic assessment of the safety of coastal structures. University of Liverpool.

Enríquez, A.R., Marcos, M., Álvarez-Ellacuría, A., Orfila, A., Gomis, D., 2017. Changes in beach shoreline due to sea level rise and waves under climate change scenarios: application to the Balearic Islands (western Mediterranean). Hazards Earth Syst. Sci 175194, 1075-1089. https://doi.org/10.5194/nhess-17-1075-2017

Grasmeijer, B.T., Ruessink, B.G., 2003. Modeling of waves and currents in the nearshore parametric vs. probabilistic approach. Coast. Eng. 49, 185-207. https://doi.org/10.1016/S0378-3839(03)00045-0 
Greenwood, C., Vogler, A., Morrison, J., Murray, A., 2018. The approximation of a sea surface using a shore mounted X-band radar with low grazing angle. Remote Sens. Environ. 204, 439-447. https://doi.org/10.1016/J.RSE.2017.10.012

Hamylton, S., 2011. The use of remote sensing and linear wave theory to model local wave energy around Alphonse Atoll, Seychelles. Estuar. Coast. Shelf Sci. 95, 349-358. https://doi.org/10.1016/J.ECSS.2011.08.035

Harris, F.J., 1978. On the use of windows for harmonic analysis with the discrete Fourier transform. Proc. IEEE 66, 51-83. https://doi.org/10.1109/PROC.1978.10837

Hasselmann, K., 1974. On the spectral dissipation of ocean waves due to white capping. BoundaryLayer Meteorol. 6, 107-127. https://doi.org/10.1007/BF00232479

Hasselmann, K., Barnett, T.P., Bouws, E., Carlson, H., Cartwright, D.E., Enke, K., Ewing, J.A., Gienapp, H., Hasselmann, D.E., Kruseman, P., Meerburg, A., Muller, P., Olbers, D.J., Richter, K., Sell, W., Walden, H., 1973. Measurements of Wind-Wave Growth and Swell Decay during the Joint North Sea Wave Project (JONSWAP), Ergnzungsheft zur Deutschen Hydrographischen Zeitschrift Reihe. Deutches Hydrographisches Institut. https://doi.org/citeulike-article-id:2710264

Holman, R.A., Stanley, J., 2007. The history and technical capabilities of Argus. Coast. Eng. 54, 477-491. https://doi.org/10.1016/J.COASTALENG.2007.01.003

Holthuijsen, L.H., 1981. The directional energy distribution of wind generated waves as inferred from stereophotographic observations of the sea surface. Delft University of Technology.

Huang, N.E., Long, S.R., Tung, C.C., Yuen, Y., Bliven, L.F., 1981. A unified two-parameter wave spectral model for a general sea state. J. Fluid Mech. 112, 203-224. https://doi.org/10.1017/S0022112081000360 
Jähne, B., Schultz, H., 1992. Calibration and accuracy of optical slope measurements for short wind waves, in: Estep, L. (Ed.), Optics of the Air-Sea Interface. International Society for Optics and Photonics, pp. 222-233. https://doi.org/10.1117/12.138851

Jiménez, J.A., Osorio, A., Marino-Tapia, I., Davidson, M., Medina, R., Kroon, A., Archetti, R., Ciavola, P., Aarnikhof, S.G.J., 2007. Beach recreation planning using video-derived coastal state indicators. Coast. Eng. 54, 507-521. https://doi.org/10.1016/J.COASTALENG.2007.01.012

Kroon, A., Davidson, M.A., Aarninkhof, S.G.J., Archetti, R., Armaroli, C., Gonzalez, M., Medri, S., Osorio, A., Aagaard, T., Holman, R.A., Spanhoff, R., 2007. Application of remote sensing video systems to coastline management problems. Coast. Eng. 54, 493-505. https://doi.org/10.1016/J.COASTALENG.2007.01.004

Larson, M., Kraus, N.C., 1994. Temporal and spatial scales of beach profile change, Duck, North Carolina. Mar. Geol. 117, 75-94. https://doi.org/10.1016/0025-3227(94)90007-8

Lippmann, T.C., Holman, R.A., 1991. Phase Speed and Angle of Breaking Waves Measured with Video Techniques, in: Coastal Sediments. ASCE, Seattle, pp. 542-556.

Mattie, M., Hsiao, S., Evans, D., 1981. Wave direction measured by four different systems. IEEE J. Ocean. Eng. 6, 87-93. https://doi.org/10.1109/JOE.1981.1145493

Menn, I., 2002. Ecological comparison of two sandy shores with different wave energy and morphodynamics in the North Sea. Universität Hamburg.

Mitsuyasu, H., Tasai, F., Suhara, T., Mizuno, S., Ohkusu, M., Honda, T., Rikiishi, K., Mitsuyasu, H., Tasai, F., Suhara, T., Mizuno, S., Ohkusu, M., Honda, T., Rikiishi, K., 1975. Observations of the Directional Spectrum of Ocean WavesUsing a Cloverleaf Buoy. J. Phys. Oceanogr. 5, 750-760. https://doi.org/10.1175/1520-0485(1975)005<0750:OOTDSO>2.0.CO;2 
Mumby, P.J., Green, E.P., Edwards, A.J., Clark, C.D., 1999. The cost-effectiveness of remote sensing for tropical coastal resources assessment and management. J. Environ. Manage. 55, 157-166. https://doi.org/10.1006/JEMA.1998.0255

Múnera, S., Osorio, A.F., Velásquez, J.D., 2014. Data-based methods and algorithms for the analysis of sandbar behavior with exogenous variables. Comput. Geosci. 72, 134-146. https://doi.org/10.1016/J.CAGEO.2014.07.009

Munk, W.H., 1951. Origin and generation of waves. Coast. Eng. Proc. 1, 1. https://doi.org/10.9753/icce.v1.1

Nieto, M.A., Garau, B., Balle, S., Simarro, G., Zarruk, G.A., Ortiz, A., Tintoré, J., ÁlvarezEllacuría, A., Gómez-Pujol, L., Orfila, A., 2010. An open source, low cost video-based coastal monitoring system. Earth Surf. Process. Landforms 35, 1712-1719. https://doi.org/10.1002/esp.2025

Ochi, M.K., Hubble, E.N., 1977. Six-Parameter Wave Spectra, in: Coastal Engineering 1976. American Society of Civil Engineers, New York, NY, pp. 301-328. https://doi.org/10.1061/9780872620834.018

Oppenheim, A., 2011. RES.6-007 Signals and Systems. [WWW Document]. Massachusetts Inst. Technol. MIT OpenCourseWare. URL https://ocw.mit.edu/resources/res-6-007-signals-andsystems-spring-2011/index.htm\# (accessed 2.12.18).

Osorio, A.F., Medina, R., Gonzalez, M., 2012. An algorithm for the measurement of shoreline and intertidal beach profiles using video imagery: PSDM. Comput. Geosci. 46, 196-207. https://doi.org/10.1016/J.CAGEO.2011.12.008

Otsu, N., 1979. A threshold selection method from gray-level histograms. IEEE Trans. Syst. Man. Cybern. 9, 62-66. 
Pérez Muñoz, J.C., Ortiz Alarcón, C.A., Osorio, A.., Mejía, C.., Medina, R., 2013. Environmental applications of camera images calibrated by means of the Levenberg-Marquardt method. Comput. Geosci. 51, 74-82. https://doi.org/10.1016/J.CAGEO.2012.07.016

Plant, N.G., Holman, R.A., 1997. Intertidal beach profile estimation using video images. Mar. Geol. 140, 1-24. https://doi.org/10.1016/S0025-3227(97)00019-4

Ruggiero, P., Côté, J., Kaminsky, G., Gelfenbaum, G., 1999. Scales of variability along the Columbia River littoral cell, in: Proceedings of Coastal Sediments. American Society of Civil Engineers, pp. 1692-1707.

Smit, M.W.., Aarninkhof, S.G.J., Wijnberg, K.M., González, M., Kingston, K.S., Southgate, H.N., Ruessink, B.G., Holman, R.A., Siegle, E., Davidson, M., Medina, R., 2007. The role of video imagery in predicting daily to monthly coastal evolution. Coast. Eng. 54, 539-553. https://doi.org/10.1016/J.COASTALENG.2007.01.009

Soares, C.G., 1984. Representation of double-peaked sea wave spectra. Ocean Eng. 11, 185-207. https://doi.org/10.1016/0029-8018(84)90019-2

Stockdon, H.F., Holman, R.A., 2000. Estimation of wave phase speed and nearshore bathymetry from video imagery. J. Geophys. Res. Ocean. 105, 22015-22033. https://doi.org/10.1029/1999JC000124

Taborda, R., Silva, A., 2012. COSMOS: A lightweight coastal video monitoring system. Comput. Geosci. 49, 248-255. https://doi.org/10.1016/J.CAGEO.2012.07.013

The SWAMP Group, 1985. Introduction: The Spectral Energy Balance, in: Ocean Wave Modeling. Springer US, Boston, MA, pp. 7-10. https://doi.org/10.1007/978-1-4757-6055-2_1

The Wamdi Group, 1988. The WAM Model—A Third Generation Ocean Wave Prediction Model. J. Phys. Oceanogr. 18, 1775-1810. https://doi.org/10.1175/1520- 
583 Yim, J.Z., Chou, C.-R., Wong, W.-K., Chen, T.-H., 2006. The Wave Field in the Coastal Area of

584 Taipei Harbour, in: The Sixteenth International Offshore and Polar Engineering Conference.

585 International Society of Offshore and Polar Engineers, pp. 566-570.

586 Yoo, J., Fritz, H., Haas, K., Work, P., Barnes, C., 2005. Wave property estimation using linear

587 feature extraction from nearshore wave images, in: The 5th International Symposium on

$588 \quad$ Ocean Wave Measurement and Analysis.

589

590

591

592

593

600

601

602
Zhang, S., Zhang, C., 2008. Application of Ridgelet Transform to Wave Direction Estimation, in: 2008 Congress on Image and Signal Processing. IEEE, pp. 690-693. https://doi.org/10.1109/CISP.2008.494

Zikra, M., 2012. Development of video image analysis methods for estimating bathymetry and the directional wave spectrum in shallow water areas. Kyushu University.

Zikra, M., Hashimoto, N., Yokota, M., Yamashiro, M., Suzuki, K., 2011. DIRECTIONAL WAVE SPECTRUM IN SHALLOW WATER WAVES USING AN ARRAY OF PIXEL BRIGTHNESS ON VIDEO IMAGES, in: Asian And Pacific Coasts 2011. WORLD SCIENTIFIC, pp. 433-441. https://doi.org/10.1142/9789814366489_0049 
603

604

605

606

607

608

609

610

611

612

613

614

615

616

617

618

619

620

621 
Table 1. Peak Period Error Analysis of Windows: BM denotes the Blackman window; TK

624 denotes the Tuckey window.

\begin{tabular}{ccc}
\hline \multicolumn{3}{c}{ Error $(\mathbf{s})$} \\
\hline \multicolumn{1}{c}{ Window } & Mean & Std. Dev \\
\hline BM $0.03-0.5 \mathrm{~Hz}$ & 4.80 & 6.23 \\
TK $0.03-0.5 \mathrm{~Hz}$ & 22.69 & 4.62 \\
BM $0.05-0.5 \mathrm{~Hz}$ & 3.04 & 3.82 \\
TK $0.05-0.5 \mathrm{~Hz}$ & 7.99 & 6.62 \\
BM $0.07-0.5 \mathrm{~Hz}$ & 1.99 & 2.53 \\
TK $0.07-0.5 \mathrm{~Hz}$ & 2.01 & 2.48 \\
\hline
\end{tabular}

625

626 Table 2. Error and agreement parameters for the study sites.

627

\begin{tabular}{lcccc}
\hline \multirow{2}{*}{\multicolumn{1}{c}{ Site }} & \multicolumn{2}{c}{ Error (s) } & \multirow{2}{*}{$\boldsymbol{r}$} & $\boldsymbol{d}$ \\
\cline { 2 - 3 } & Mean & Std. Dev. & & \\
\hline Cala Millor & 0.82 & 1.15 & 0.84 & 0.91 \\
Playa de Palma & 1.79 & 2.69 & 0.02 & 0.72 \\
Bunkerhill & 2.02 & 2.46 & 0.63 & 0.79 \\
Bocagrande & 0.82 & 0.67 & -0.09 & 0.38 \\
\hline
\end{tabular}

628

629

630

631

632

633 

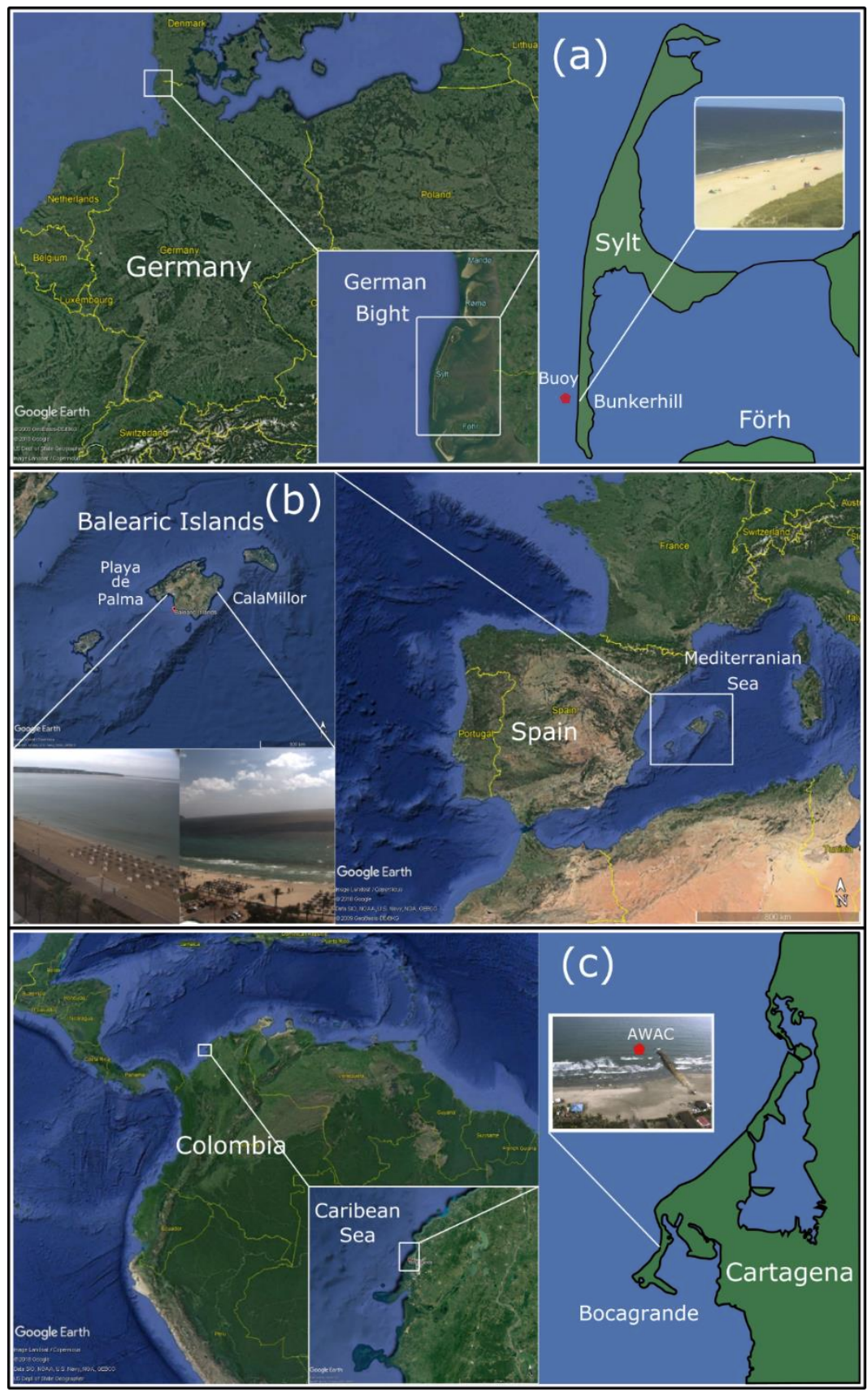

637

638 FIG 1. Study sites: (a) Bunkerhill beach; (b) Playa de Palma and Cala Millor beaches; and (c) 639 Bocagrande beach. 
641

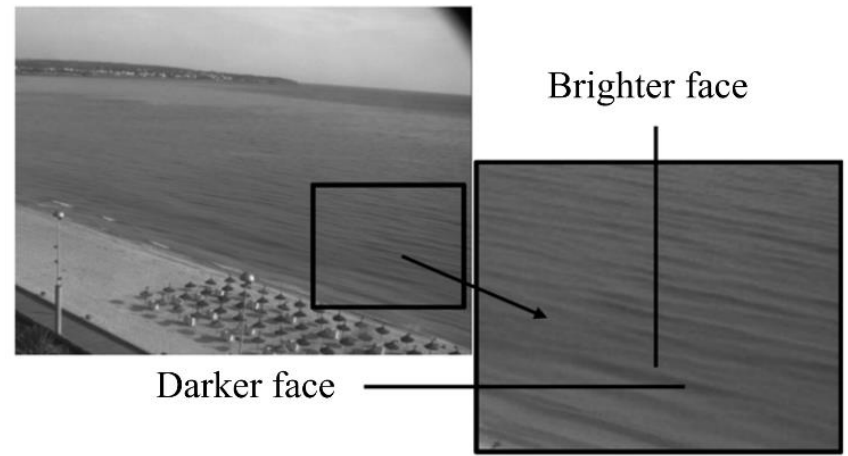

642

643 FIG 2. Visual wave features: dark frontal face and bright back face.

644
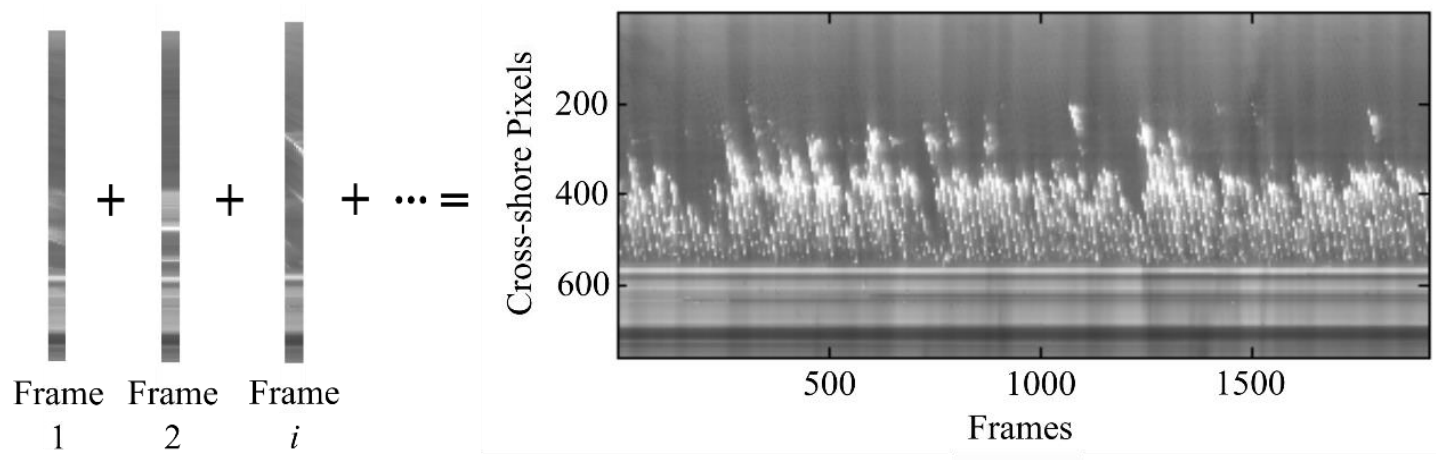

646

647 FIG 3. Time-stack image: (a) pixel column concatenation; and (b) resulting time-stack. 


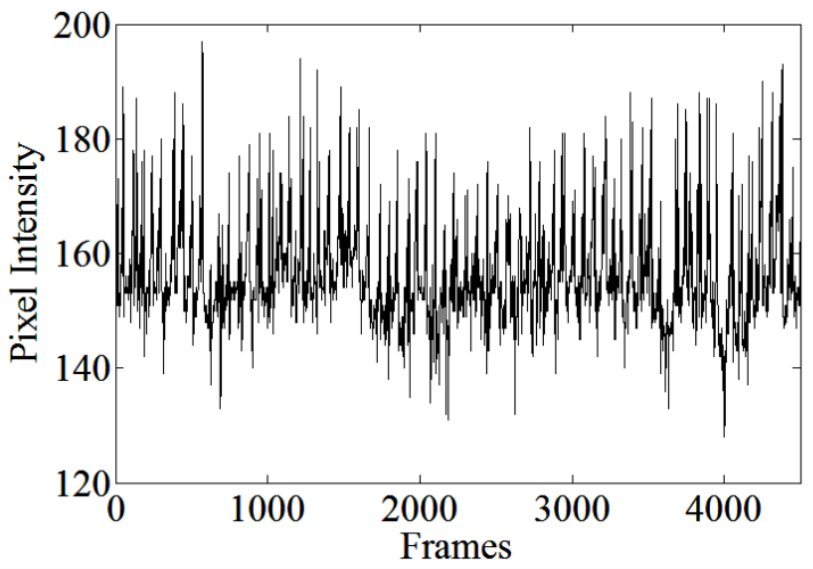

650 FIG 4. Example of one row of pixel intensity time series.

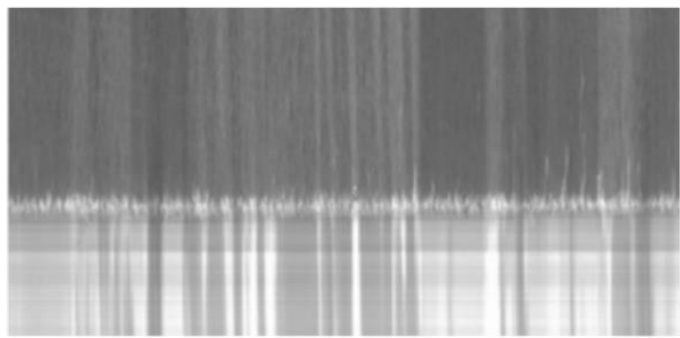

(a)

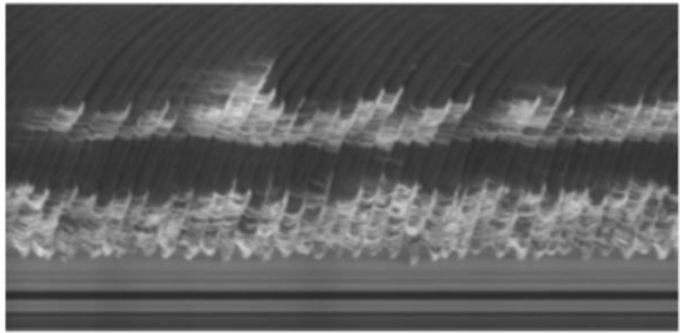

(b)

651

652

653 FIG 5. Sources of noise in timestack images: (a) Environmental illumination (clouds) changes 654 viewed in time-stack image; $(b)$ Foam from breaking waves viewed in time-stack image. 


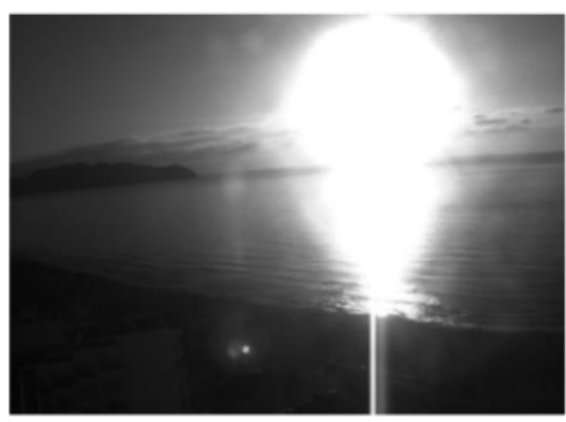

(a)

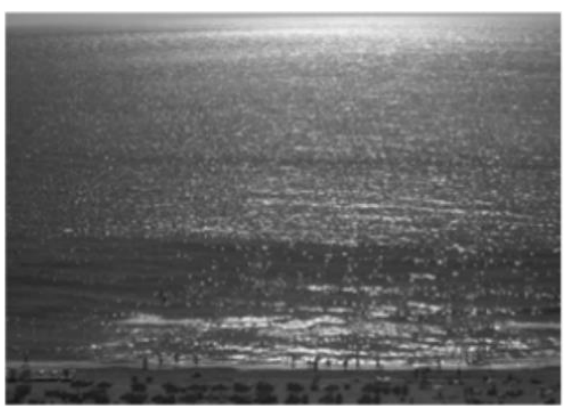

(c)

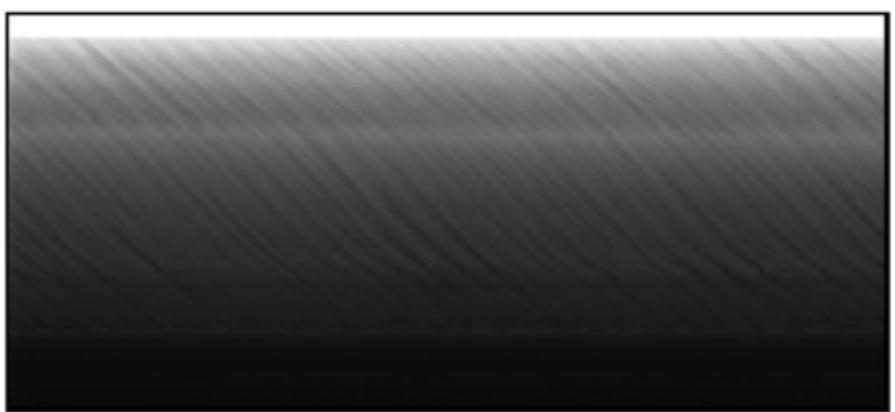

(b)

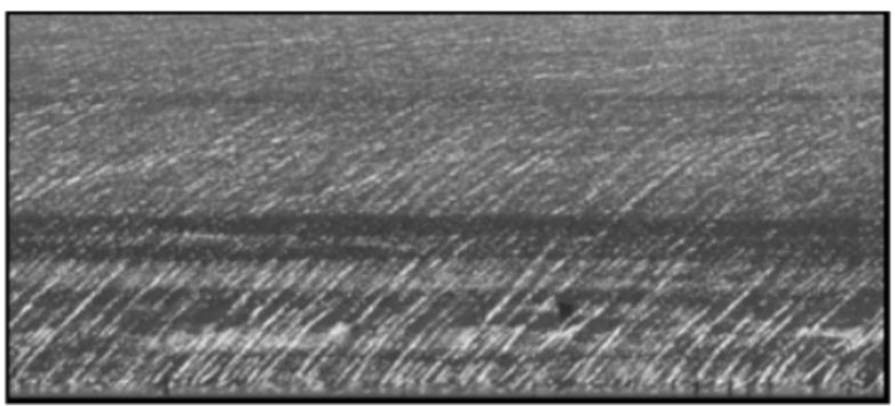

(d)
656

657

658

659

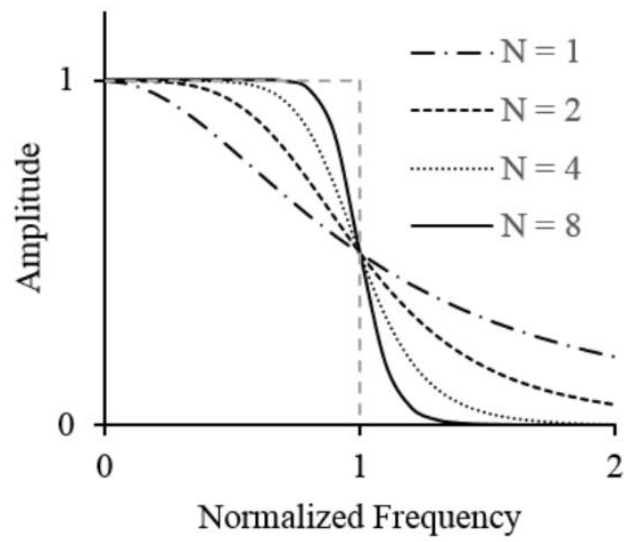
time-stack image.

660

FIG 6. Sources of noise in timestack and snapshot images: incidence of direct sunlight in $(a)$ snap-shot image and $(b)$ time-stack image; and sun glittering in $(c)$ snap-shot image and $(d)$

661 FIG 7. Butterworth filter shape for different filter orders (N) 


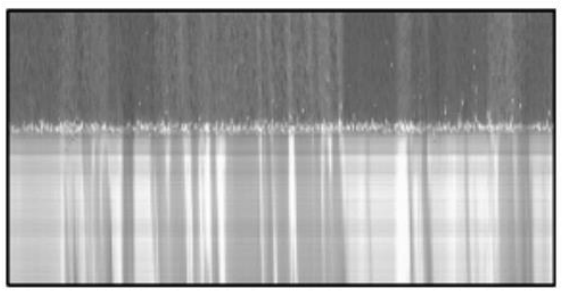

(a)

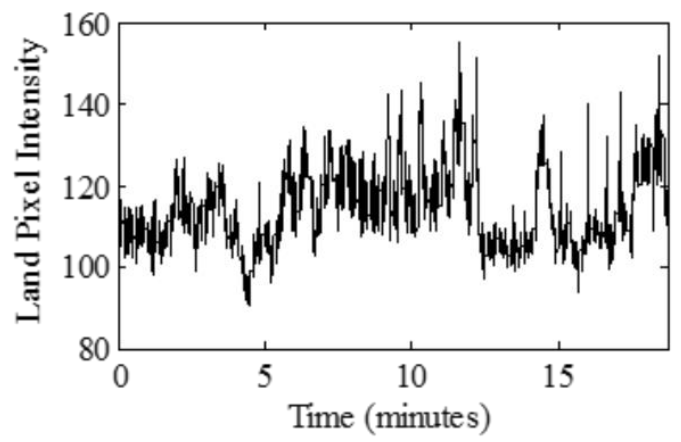

(b)

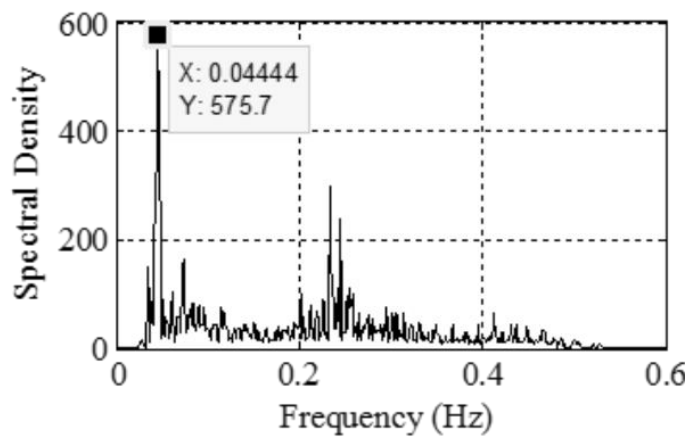

(c)

662

663 FIG 8. Environmental sunlight noise: (a) time-stack image feature; (b) average pixel intensity 664 series in a land region; (c) corresponding spectral representation. 


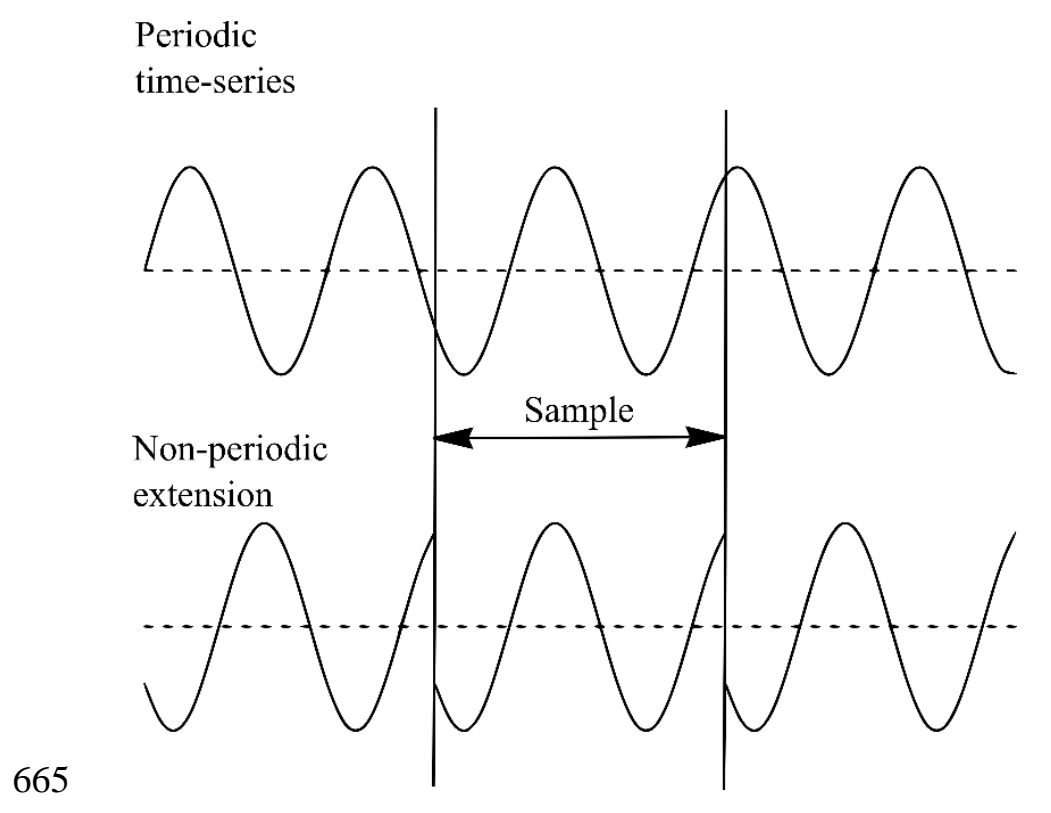

666 FIG 9. Non-periodic extension for a sample of periodic series. 


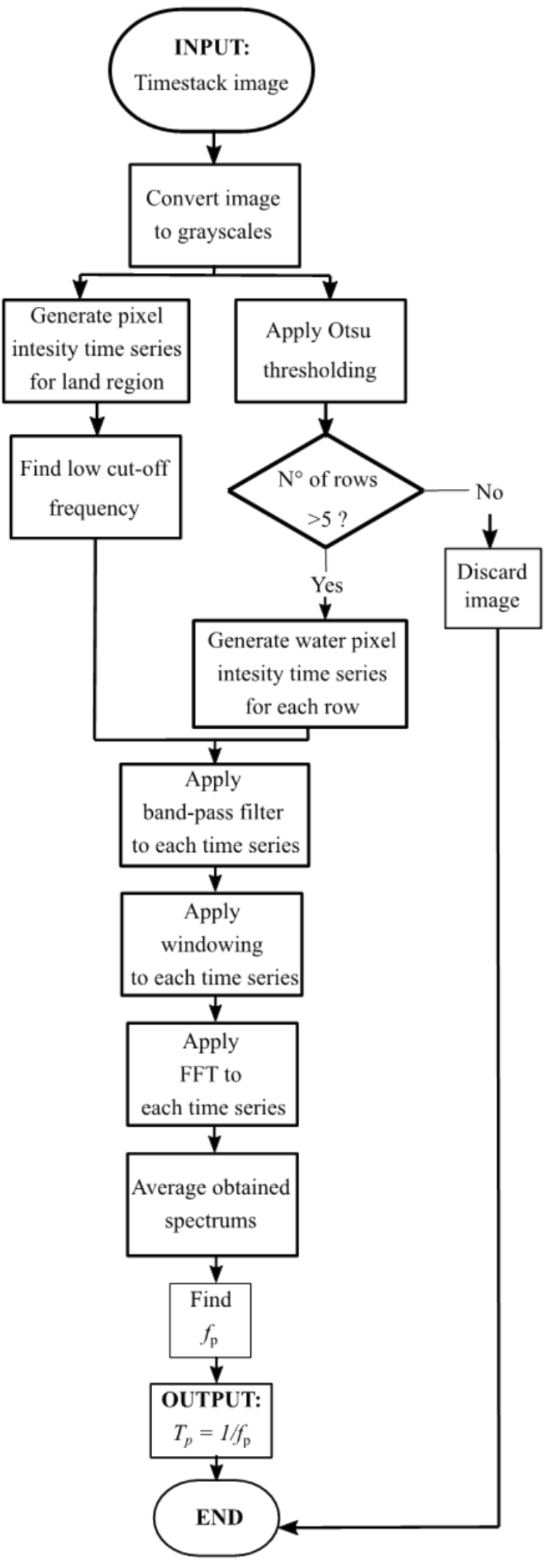

668 FIG 10. Algorithm flow-chart. 


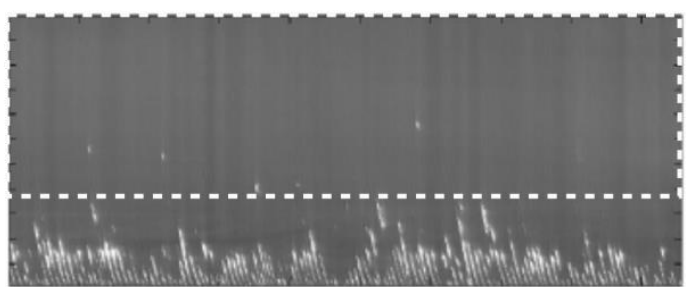

(a)

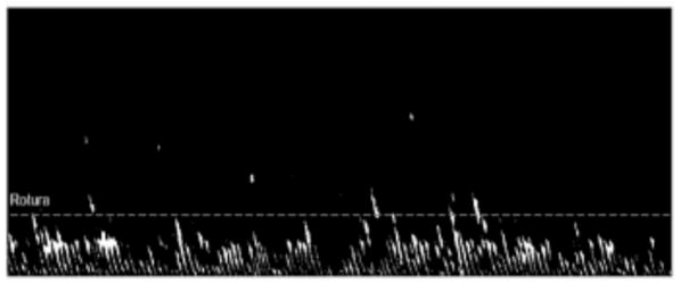

(b)

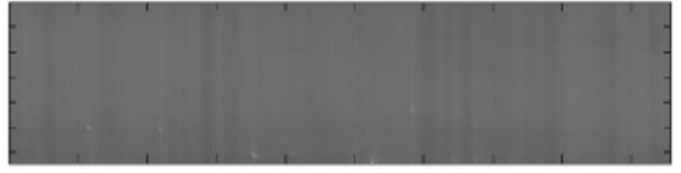

(c)

669

670 FIG 11. Otsu thresholding procedure: (a) Timestack image; (b) Binarized image; and (c) Selected 671 rows. 


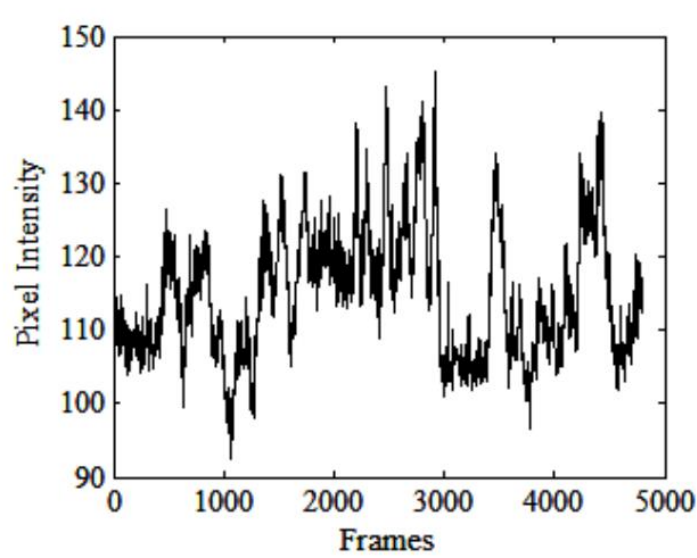

(a)

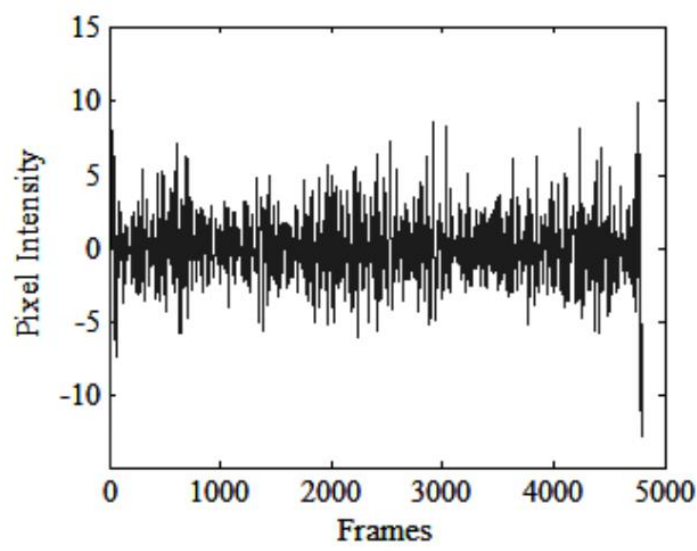

(c)

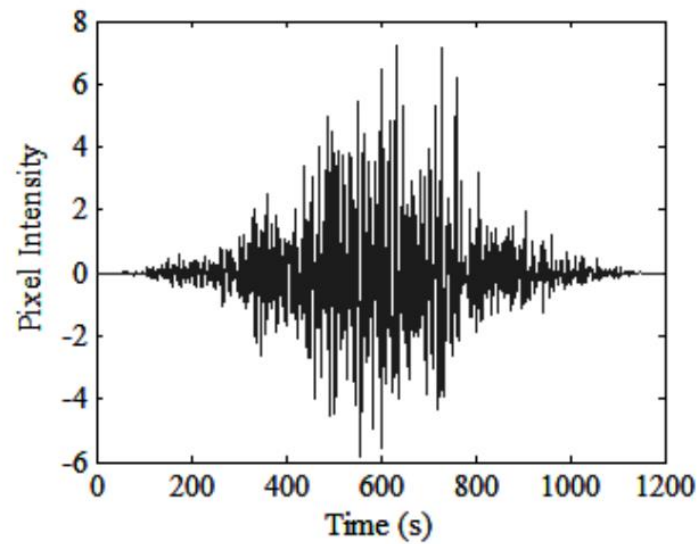

(e)

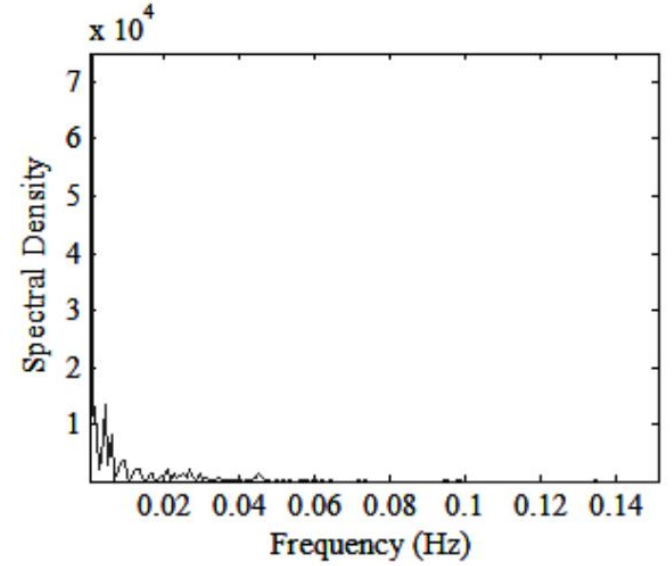

(b)

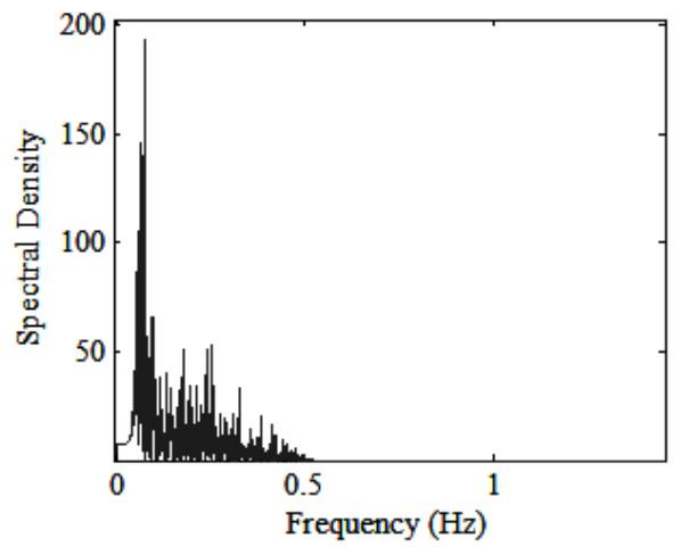

(d)

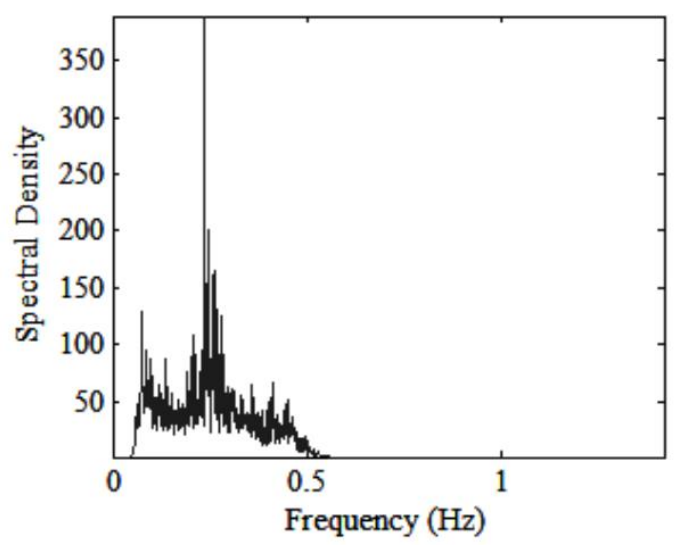

(f) 
673 FIG 12. Pixel intensity time series processing: Unfiltered time series - (a) Pixel intensity series 674 and (b) Frequency spectrum; Filtered time series - (c) Pixel intensity series and (d) Frequency 675 spectrum; and Windowed time series - (e) Pixel intensity series and (f) Frequency spectrum.

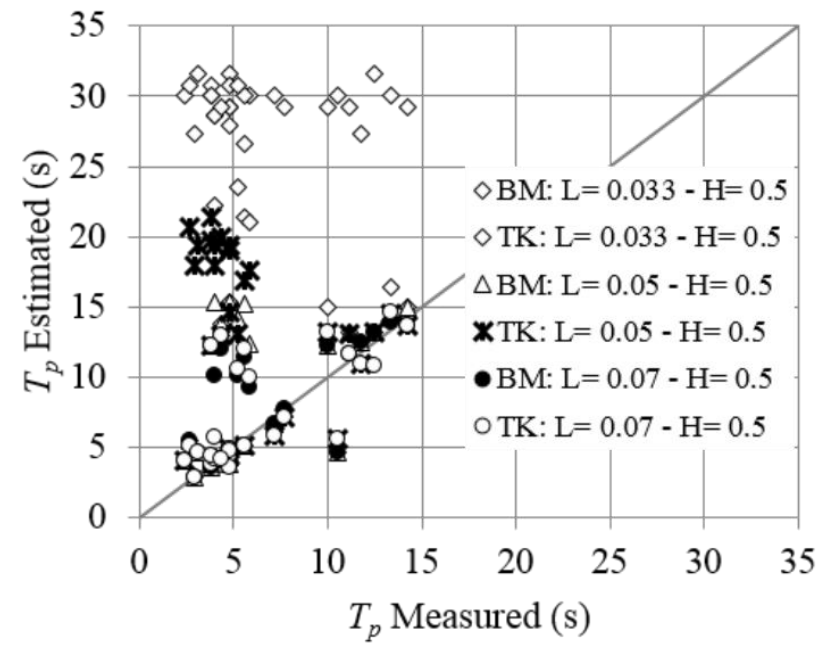

676

FIG 13. Window comparison for Bunkerhill data: BM denotes the Blackman window; TK denotes the Tuckey window; L denotes low cut-off frequency in $\mathrm{Hz}$; and $\mathrm{H}$ denotes high cutoff frequency in $\mathrm{Hz}$. 


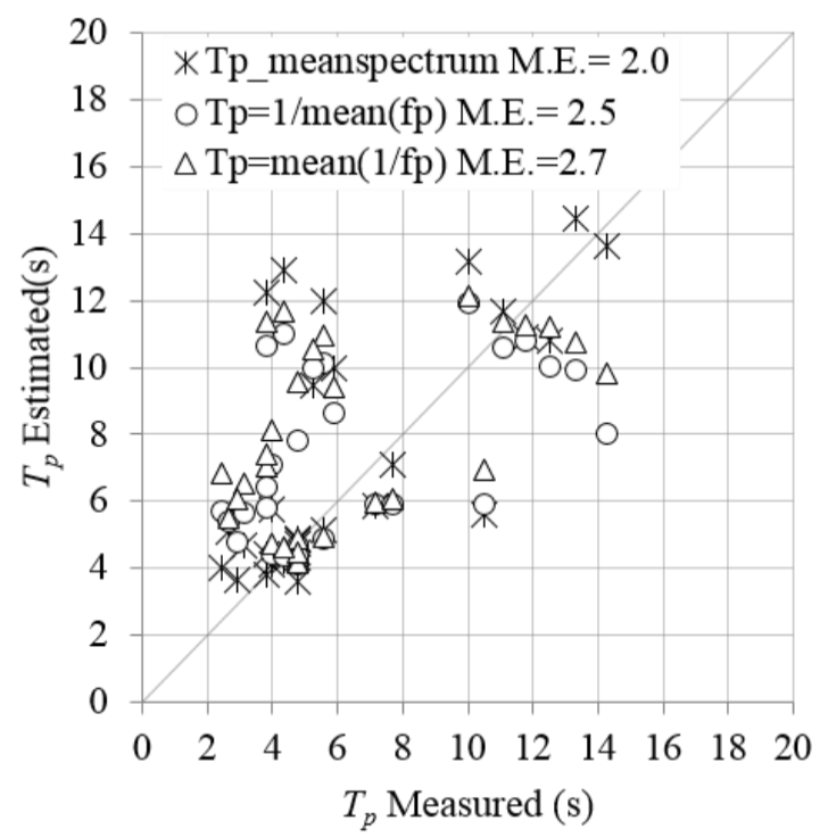

680

681 FIG 14. Comparison of peak period approaches

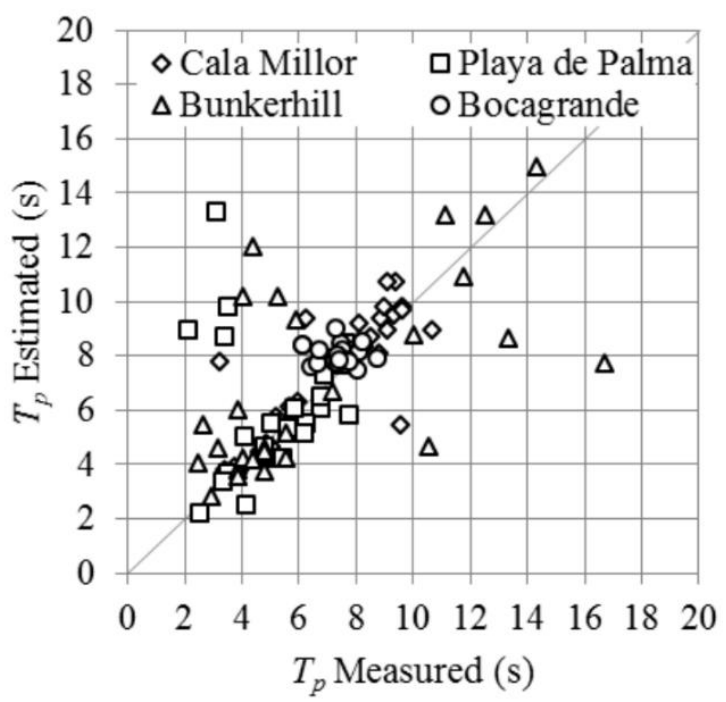

682

FIG 15. Estimated vs. measured $T_{p}$ for the whole data set. 


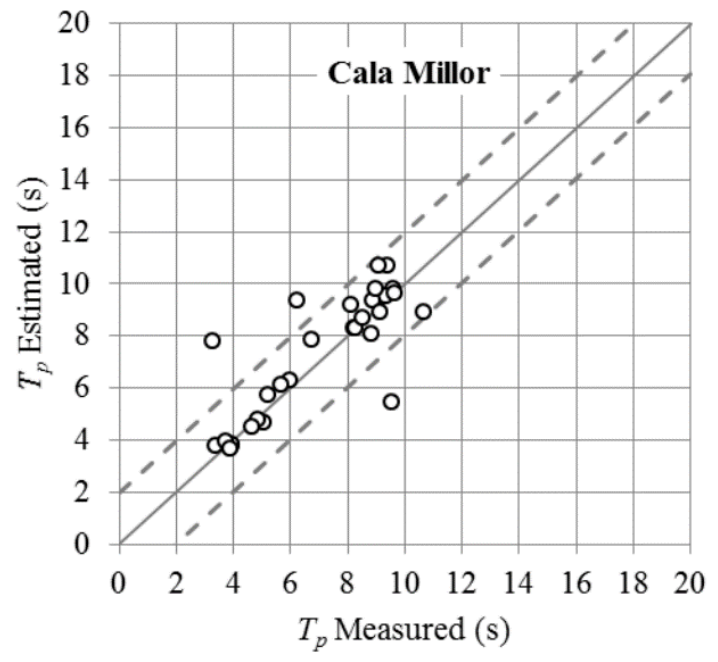

(a)

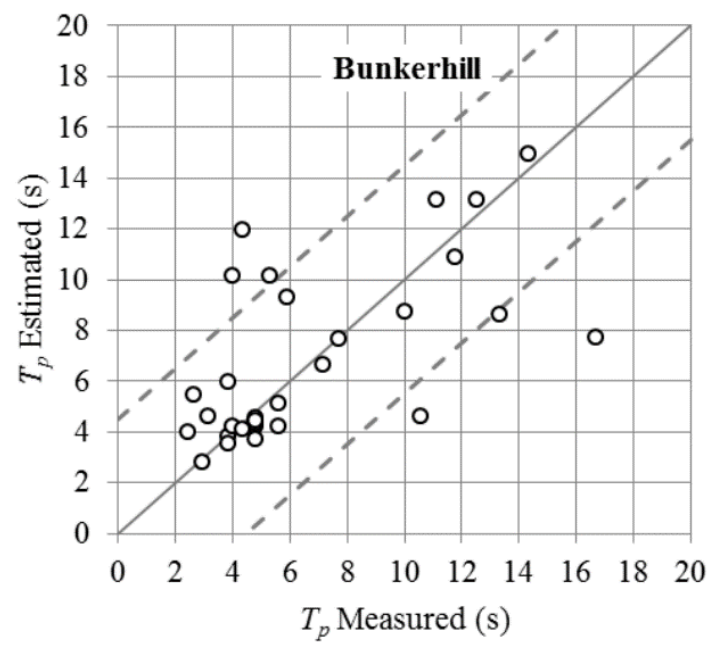

(c)

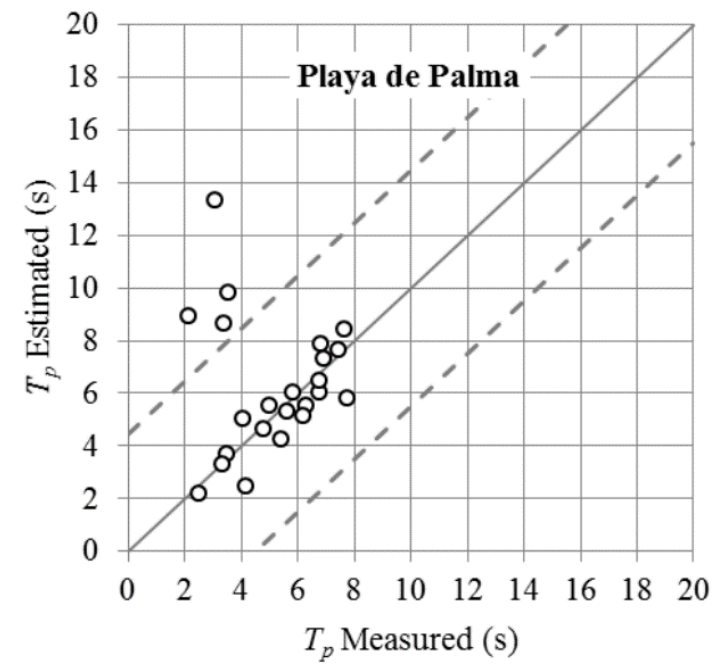

(b)

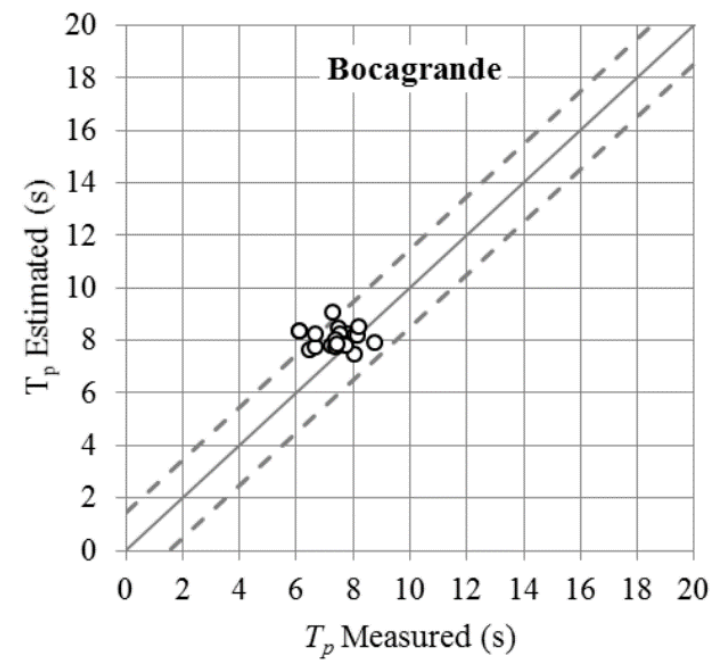

(d)

FIG 16. Estimated vs. Measured $T_{p}$ for: (a) Cala Millor beach; (b) Playa de Palma beach; $(c)$ 